\title{
Hedge Fund Return Dynamics: \\ Long memory and Regime switching
}

February, 2014

M. A. LIMAM ${ }^{1}$

LAMETA University of Montpellier I
V. TERRAZA ${ }^{2}$

CREA University of Luxembourg

\author{
M. TERRAZA ${ }^{3}$ \\ LAMETA-CNRS \\ University of Montpellier I
}

\begin{abstract}
:
This paper investigates the dynamics of hedge fund returns and their behavior of persistence in a unified framework through the Markov Switching ARFIMA model of Härdle and Tsay (2009). Major results based on the CSFB/Tremont hedge fund indexes monthly data during the period 1994-2012, highlight the importance of the long memory parameter magnitude i.e shocks in shaping hedge fund return dynamics and show that the hedge fund dynamics are characterized by two levels of persistence: in the first one, associated to low-volatility regime, hedge fund returns are a stationary long memory process whereas in the second one, associated to high-volatility regime, returns exhibit higher parameter of fractional integration. More precisely, in high volatility regime i.e periods of turmoil, the process tends to be nonstationary but still exhibits a mean-reverting behavior. The findings are interesting and enable us to establish a relationship between hedge fund return states and memory phenomenon.
\end{abstract}

Keywords: Hedge Funds, Persistence, Markov Switching ARFIMA.

\section{Introduction :}

\footnotetext{
1 Corresponding author.Department of Economics, LAMETA, University of Montpellier1 Avenue Raymond Dugrand, Site de Richter CS 79606, Montpellier Cedex 1,France, E-mail : mohamed-ali.limam@lameta.univmontp1.fr

${ }^{2}$ CREA, University of Luxembourg Faculty of Law Economics and Finance 162a, avenue de la faïencerie L1511 Luxembourg, E-mail: virginie.terraza@uni.lu

${ }^{3}$ Department of Economics, LAMETA, University of Montpellier 1 Avenue Raymond Dugrand, Site de Richter CS 79606, Montpellier Cedex 1, France, E-mail : michel.terraza@lameta.univ-montp1.fr
} 
It's taking for granted that hedge fund industry has grown dramatically during past decades to constitute a global business at the forefront of investment innovation. According to Hedge Fund Research the industry peaked at \$1.9 trillion in 2007. Despite this apparent success, recent crisis reveals the necessity to enhance our understanding of the hedge fund return dynamics.

One relevant fact of empirical studies dedicated to hedge funds is performance evaluation: Fung and Hsieh (1997, 2000) Ackerman, McEnally and Ravencraft (1999), Brown, Gotzmann and Ibboston (1999) and Adwards and Liew (1999), among others compared the returns earned on a hedge fund with other earned on standard assets. Earlier approaches consisted in using linear factor or non-parametric models. However, many authors have shown that hedge fund returns exhibit non-linear dynamics and asymmetry since managers try to obtain high performance using highly leveraged dynamics and complex instruments based on option or other nonlinear derivates: Fung and Hsieh (1997, 2000), Agarwal and Naik (2004) and Amenc et al. (2004). Fung and Hsieh (1997, 2000) mentioned that linear factor model can only explain a minor proportion of the observed nonlinearity of hedge funds returns. Consequently, taking into account such stylized facts observed on hedge fund returns require focusing on nonlinear modeling able to capture asymmetry and sudden changes in correlation. Intuitively, many authors propose a regime switching approach to model hedge fund returns: To establish a measure of systemic risk which takes into account market states, Chan, Getmansky, Haas and Lo (2005) applied a simple two state markov switching model to the CSFB/Tremont indexes. Using the same data, Billio, Getmansky and Pellizon (2006) investigated dynamic risk exposure of hedge funds using regime switching beta model. Their findings suggest that this modeling allow capturing time varying risk exposure for hedge funds conditional on different market states. The authors cite several reasons to fit hedge fund returns using regime switching models. Bruder, Koudiraty, Darolles and Roncalli (2010) consider regime switching models for hedge funds in the context of portofolio allocation. Recently, Jawadi and Khanniche (2012) have studied the adjustment dynamics of hedge fund returns and their exposure to risk factors using smooth transition regression (STR) model of Granger and Teäsvitra (1993). They showed that hedge funds asymmetry and non-linearity can be reproduced using STR model.

Also, in the areas of hedge fund performance evaluation, one important question is performance persistence. At this stage, a distinction must be made between two approaches: relative persistence and pure persistence. In evaluating relative persistence, funds of the same strategies are classified as winners and losers depending on their performance relative to the median return over a given period. Evidence of persistence is found when winners and/or losers maintain classification for two subsequent periods. The majority of studies ${ }^{4}$ investigated relative persistence in hedge fund returns: Park and Staum (1998), Agarwal and Naik (2000), Koh, Koh and Teo (2003), Agarwal et al (2007). According to Gehin (2005), these studies are heterogeneous and their results are mitigated since conclusion depends on

\footnotetext{
${ }^{4}$ Eling (2009) and Géhin (2005) for a detailed litterature revue.
} 
certain factors (data, periods, procedures ...). Chand and al. (2005) mentioned that persistence in performance is indirectly linked to serial correlation since it usually implies positively autorcorrelated returns. Obviously, this link is strengthened when dealing with pure persistence.

While the relative persistence tests require a whole sample of funds, the pure persistence involves performance of a fund without considering other funds at the same time. The commonly used method to check the existence of pure persistence is the calculation of the Hurst exponent. De Souza and Gokcan (2004) use the Hurst exponent combined with a Dstatistic to study a relatively small sample of funds. They found that the funds exhibiting the strongest persistence of positive returns during in sample period (36 months) showed a better risk-adjusted profile in the out of sample period. Amenc, El Bied and Martellini (2003) calculated the Hurst exponent for the CSFB/Tremont hedge fund indexes to analyze the predictability of hedge fund returns and show evidence of persistence for eight of the nine studied series. The Hurst exponent can be considered as a useful tool to evaluate performance persistence. However this estimate is biased when long-range dependence is absent and its distribution is unknown so that we can't test its statistical significance. This coefficient is related to the long memory parameter $d$ by the equation $d=H-1 / 2$. This equation offers a convenient link to reconcile the notion of long memory or fractional integration and hedge fund performance pure persistence. Moreover, regime switching modeling and further persistence in hedge fund returns through the calculation of the Hurst exponent prove that hedge fund return dynamic is very complicated. This lead us to raise several questions concerning the hedge fund adjustment and whether the observed persistence is a true or a spurious one since fractionally integrated process are considered as a competing framework modeling against structural change and regime switching models. Here we bring a recent debate on long memory process to the area of hedge fund return modeling that will be discussed in next section.

In this paper, we aim to enhance our understanding of hedge fund return dynamics and extend previous literature by combining the hedge fund return modeling and the performance persistence in a unified framework. Our approach differs from the previous work since we employ a univariate model of hedge fund returns which takes into account several features of financial time series such as regime switching and long memory. Several econometric tools will be used to achieve this goal. We address the performance of hedge funds in terms of pure persistence in a general way using the notion of long memory. In particular, we investigate the dynamics of hedge fund returns using the MS-ARFIMA model of Tsay and Härdle (2009). This model combines two important characteristics of economic and financial time series: long memory through fractional integration behavior and Markov regime switch since break points are selected endogenously. The rest of the paper is organized as follows: Section 2 describes the methodology used and presents the econometric framework employed. Section 3 introduces the MS-ARFIMA model. Section 4 presents the data and major results and Section 5 concludes.

\section{Long memory versus regime shifts:}


The notion of long memory or long range dependence appears in various empirical studies and in several areas of application, including hydrology, economics and finance. This concept presents a particular interesting case since it allows the intermediate case between the two alternatives of $\mathrm{I}(0)$ and $\mathrm{I}(1)$ process. The long memory process can be defined equivalently ${ }^{5}$ in time and frequency domain. In the time domain, a series exhibits long memory if the absolute values of the autocorrelations are not summable. More precisely, any stationary process $X_{t}$ is a long memory process if $\lim _{n \rightarrow \infty} \sum_{j=0}^{n}|\rho k|$ is not finite, where $\rho k$ the autocorrelation function of $X_{t}$ at lag $k$. However, there are alternative definitions. In particular, long memory can be defined by specifying a hyperbolic decay of the autocorrelations: any stationary process $X_{t}$ is a long memory process if $\rho_{k} \square k^{2 d-1} L_{1}(k)$ as $k \rightarrow \infty$, where $L_{1}($.) denote a slowly varying function $^{6}$. In the frequency domain, a series exhibits long memory it the spectral density is unbounded at frequency zero. Specially, any stationary process $X_{t}$ with spectral function $f(\lambda)$ is a long memory process if $f(\lambda) \square|\lambda|^{2 d-1} L_{2}(1 / \lambda)$ as $\lambda \rightarrow 0^{+}$, where $L_{2}$. denotes a slowly varying function. The real $d$ is the so-called long memory parameter and it's connected to the Hurst exponent by the equality $d=H-\frac{1}{2}$. The two parameters display the long memory property of a series and its level of persistence. According to the values taken by the Hurst exponent and the parameter of fractional integration, three cases can be distinguished:

- If $H=\frac{1}{2} \Leftrightarrow d=0$ : Short memory (no persistence).

- If $\frac{1}{2}<H<1 \Leftrightarrow 0<d<\frac{1}{2}$ : Long memory (persistance).

- If $0<H<\frac{1}{2} \Leftrightarrow-\frac{1}{2}<d<0$ : Intermediate memory (Anti-persistence)

During last decades, fractionally integrated process has evolved into a vital and important part of the time series analysis. Moreover, recent studies have shown that long memory phenomenon observed in some series may be generated by a nonstationary process with structural breaks. Indeed, time series with structural breaks can induce a strong persistence in the autocorrelation function and hence generate "spurious" long memory. Thus, there is a risk of confusion between long memory and structural break. Engle and Smith (1999), Dieblod and Inoue (2001), Gourieroux and Jasiak (2001), Granger and Hyung (2004) and Perron and $\mathrm{Qu}$ (2006) demonstrate this fact using analytic and simulation evidence. Lien and Yang (2009) showed that the adjustment of the break at the expense of the long memory hypothesis implies an improvement of hedging strategies for six pairs of exchange rates. In finite sample,

\footnotetext{
${ }^{5}$ These definitions are equivalent under certain conditions Beran (1994) Theorem 2.1 for more details.

${ }^{6} L x$ is said to be a slowly varying function if and only of for any c>0, $L c x / L x$ converges to 1 as $\mathrm{x}$ tends to infinity
} 
some process may exhibit a behavior similar to that of long memory process, both in terms of the autocorrelation function (slow decay) and in terms of the spectral density (pole at frequency zero). In the same context, some authors have proposed models that can generate spurious long memory:

- Mean-plus-noise model : Diebold and Inoue (2001) and Granger and Hyung (2004)

$$
X_{t}=\mu_{t}+\varepsilon_{t}, \mu_{t}=\mu_{t-1}+v_{t}, \quad v_{t}=\left\{\begin{array}{l}
0: p \\
w_{t}: 1-p
\end{array} \text {. where } \varepsilon_{t} \square N \quad 0, \sigma_{\varepsilon}^{2} \text { et } w_{t} \square N 0,1\right.
$$

- $\quad$ STOPBREAK model : Engle and Smith (1999)

$$
X_{t}=\mu_{t}+\varepsilon_{t}, \quad \mu_{t}=\mu_{t-1}+\frac{\varepsilon_{t-1}^{2}}{\gamma+\varepsilon_{t-1}^{2}} \varepsilon_{t-1}, \varepsilon_{t} \square N \quad 0,1
$$

- Markov switching model : Diebold and Inoue (2001)

$$
X_{t}\left\{\begin{array}{ccc}
N & 0, \sigma^{2} & s_{t}=0, \\
N & 0,1 & s_{t}=1,
\end{array}\right\} \quad M=\left(\begin{array}{cc}
p_{00} & 1-p_{00} \\
1-p_{11} & p_{11}
\end{array}\right) \text { Transition probability matrix and } s_{t} \text { a }
$$

first-order-markov process taking the value 0 or 1 .

Many papers highlighted the relationship between long memory and regime switching models by analyzing several cases where regime switching models may be described as an I(d) process. The main idea behind this finding is the following: as the number of regime switching decreases (i.e. as $p 11$ and $p 22$ approach unity in the Markov switching case), the process will closely resemble a fractionally integrated series. Moreover, the size of the parameter shifts will also be a factor to take into account because larger magnitudes of breaks will introduce more persistence in the series.

On the other hand, several other studies have demonstrated the ability of long memory process to model economic and financial data highlighting their predictive power above that of ARMA, GARCH process and their extensions (Andersen et al. (2003) and Bharwaj and Swanson (2006)). Hsu (2005) reports that the U.S. inflation rates have strong dependence even after the breaks in the mean are allowed. Choi and Zivot (2005) estimate the $d$ of an exchange rate forward discount series after adjusting for breaks in their mean. Choi and Zivot find that allowing for structural breaks reduces the persistence of the forward discount but there is still evidence of long memory. Parallel to this literature that highlights the risk of confusion long memory and structural breaks or shifts, we are now witnessing a new generation of tests which aim to separate the two phenomenon and to distinguish between the true and spurious long memory: Berkes et al. (2006), Giraitis et al. (2006), Shimotsu (2006), Mayoral (2006), Ohanissian et al. (2008), Qu (2008) and Perron and Qu (2010). A major results of these studies is that a pure $I(d)$ process may not explain all of the persistence a time series, but the data do not support an extreme view that structural breaks account for all the observed persistence.

\section{MS-ARFIMA Model :}


A well-known class of long memory process is the Autoregressive Fractionally Integrated Moving Average ARFIMA(p,d,q) model, introduced by Granger and Joyeux (1980) and Hosking (1981). Formally, the process $X_{t}$ is said to be an $\operatorname{ARFIMA}(\mathrm{p}, \mathrm{d}, \mathrm{q})$ process with $d \in\left(-\frac{1}{2}, \frac{1}{2}\right)$ if it satisfies the following equation:

$$
\Phi(L)(1-L)^{d} X_{t}=\Theta(L) \varepsilon_{t}
$$

Where $(1-L)^{d}$ is a fractional differencing operator defined by the binomial expansian:

$$
(1-L)^{d}=\nabla^{d}==\sum_{k=0}^{\infty} \frac{\Gamma(k-d)}{\Gamma(-d) \Gamma(k+1)} L^{k}
$$

$\Phi(L)=1-\phi_{1} L-\ldots-\phi_{p} L^{p}$ and $\Theta(L)=1-\theta_{1} L-\ldots-\theta_{q} L^{q}$ are the autoregressive and movingaverage operators of order $\mathrm{p}$ and $\mathrm{q}$, respectively. $\varepsilon_{t} \square N\left(0, \sigma^{2}\right)$.

Let $\quad s_{t}{ }_{t=1}^{T}$ be the latent path of N-state Markov chain. At each time $s_{t}$ can assume only integer value of $1,2, \ldots, \mathrm{N}$ and its transition probability matrix is :

$$
M \equiv\left(\begin{array}{ccccc}
p_{11} & p_{21} & \cdot & \cdot & p_{N 1} \\
p_{12} & p_{22} & \cdot & \cdot & p_{N 2} \\
\cdot & \cdot & \cdot & \cdot & \cdot \\
\cdot & \cdot & \cdot & \cdot & \cdot \\
p_{1 N} & p_{2 N} & \cdot & \cdot & p_{N N}
\end{array}\right)
$$

Where $p_{i j}=P \quad s_{t}=j / s_{t-1}=i$ and $\sum_{j=1}^{N} p_{i j}=1 \quad \forall i$.

Tsay and Hardle (2009) combine the defining feature of a Markov chain and that of an $I(d)$ process. We keep authors notation, and refer the reader to the original paper for a more detailed exposition. $w_{t}$ is said to be an MS-ARFIMA(p,d,q) model if :

$$
\begin{gathered}
w_{t}=\mu_{S_{t}} I t \geq 1+1-L^{d_{S_{t}}} \sigma_{S_{t}} z_{t} I t \geq 1 \\
\left(1-\phi_{1} L\right) z_{t}=1-\theta_{1} L \varepsilon_{t}
\end{gathered}
$$

Where $I$. is the indicator function and $z_{t}$ is a stationary process with mean zero and bounded positive spectral density and independent of $S_{t}$. Tsay and Härdle (2009) suggest the use of the Durbin-Levinson-Viterbi's algorithm to perform estimation of the model. The MS- 
ARFIMA model combines two important characteristics of economic and financial time series: persistence through fractional integration behavior and Markov regime switch since break points are selected endogenously.

\section{Empirical study :}

Our methodology is motivated by the dynamics of Hedge Fund returns and their behavior of persistence. In this section, we will proceed as follow: first, we describe the data. We will check the stationarity of the CSFB/Tremont hedge fund indices and detect further existence of structural break. Long memory estimation procedure will be employed in order to test possible fractional integration. Besides, tests against spurious long memory will indicate whether the observed persistence is a true or spurious one. Estimations will be based on the Markov switching ARFIMA (MS-ARFIMA) model.

Figure1. CSFB/Tremont hedge fund indexes 1994-2012

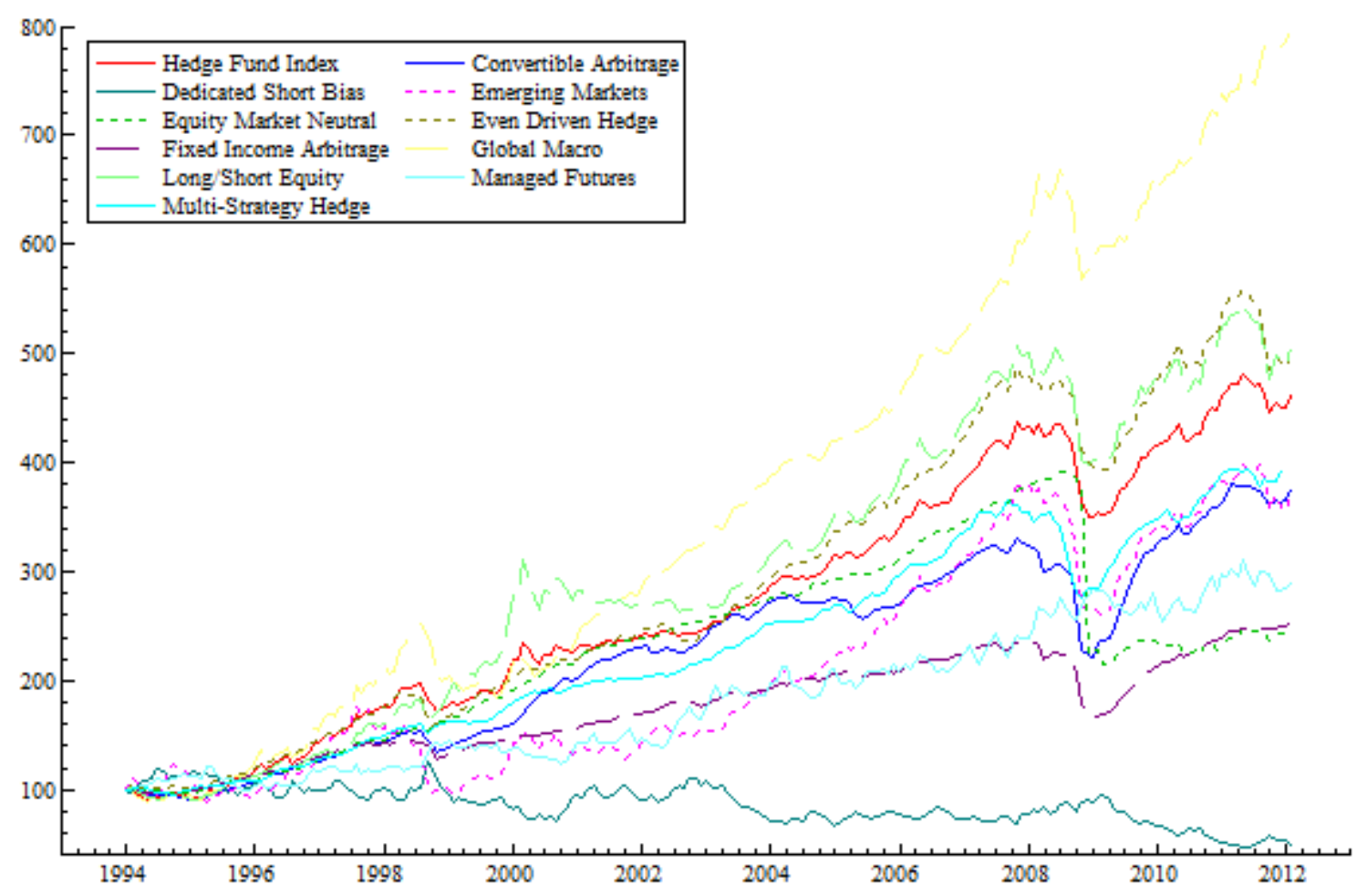

\subsection{Data and unit root tests:}

The study considers monthly data of the CSFB/Tremont ${ }^{7}$ hedge fund indexes and covers the period starting January 1994 and ending January 2012 for a total of 217 observations. The last 12 monthly returns are kept to the out of sample analysis while the first subset is reserved for the in-sample analysis. Our data consist of one hedge fund general index and ten strategy subindexes: convertible arbitrage, dedicated short bias, emerging market, equity market neutral,

\footnotetext{
${ }^{7}$ Lhabitant (2001), Amenc, El Bied and Martellini (2003) mentioned the advantages that the CSFB/Tremont hedge fund indexes offer over their competitor.
} 
even driven, fixed-income arbitrage, global macro, long-short equity, managed future and multi-strategy. This period includes several crises that happened in the last two decades i.e. the Mexican, Asian, Russian, LTCM crisis as well as the IT bubble in 2000 and the subprime crisis in 2008. The historical evolution of the 10 strategy indices and the general index are plotted in figure 1. It reveals that this last crisis has a huge impact on most hedge fund strategies. Table 1 reports the descriptive statistics of the ten CSFB/Tremont hedge fund indexes. All hedge funds exhibit positive mean, except dedicated short bias $(-0.3 \%)$, with the highest values for global macro (1\%), even driven and long-short equity $(0.8 \%)$. Dedicated short bias, emerging market and managed future exhibit relatively high volatility, some other hedge funds have lower volatility such as even driven and fixed income arbitrage. Concerning the third and the fourth moment of the distribution, hedge funds are characterized by skewed returns and excess kurtosis. Leptukortic and asymmetrical effects are mainly illustrated through Convertible Arbitrage, Equity Market Neutral, Even Driven and Fixed Income Arbitrage. Consequently, the null hypothesis of normality of the Jarque-Bera test is rejected for all series except for managed future. This result is not surprising due to the occurrence of several extreme values in financial time series relatively to the standard normal distribution in addition to hedge fund characteristics such as illiquidity, leverage and short selling.

Table 1 Descriptive statistics for the CSFB/Tremont hedge fund indexes, 1994-2011

\begin{tabular}{lcccccccc}
\hline \hline Series & OBS & Min $(\%)$ & Mean $(\%)$ & $\operatorname{Max}(\%)$ & $\mathrm{SD}(\%)$ & Skweness & Kurtosis & JB \\
\hline Hedge Fund Index & 204 & -7.8 & 0.7 & 8.2 & 2.2 & -0.36 & 5.52 & 58.83 \\
Convertible Arbitrage & 204 & -13.5 & 0.6 & 5.6 & 2.1 & -3.07 & 21.21 & 3157.4 \\
Dedicated Short Bias & 204 & -12 & -0.3 & 20.5 & 4.8 & 0.49 & 3.80 & 14.01 \\
Emerging Markets & 204 & -26.2 & 0.7 & 15.2 & 4.4 & -1.22 & 9.76 & 442.74 \\
Equity Market Neutral & 204 & -51.8 & 0.4 & 3.6 & 3.8 & -12.59 & 172.57 & $2.51 \mathrm{E}+05$ \\
Event Driven & 204 & -12.5 & 0.8 & 4.1 & 1.8 & -2.69 & 18.34 & 2259.2 \\
Fixed Income Arbitrage & 204 & -15.1 & 0.4 & 4.2 & 1.8 & -4.61 & 35.07 & 9516.3 \\
Global Macro & 204 & -12.3 & 1 & 10.1 & 2.9 & -0.25 & 6.66 & 117.04 \\
Long Short Equity & 204 & -12.1 & 0.8 & 12.2 & 2.8 & -0.23 & 6.46 & 104.72 \\
Managed Futures & 204 & -9.8 & 0.5 & 9.5 & 3.4 & -0.09 & 3.03 & 0.295 \\
Multi-Strategy & 204 & -7.6 & 0.6 & 4.1 & 1.5 & -1.89 & 9.82 & 521.3 \\
\hline \hline
\end{tabular}

In order to check the stionarity of our series we call two classes of unit root tests. The first class includes three standard unit root tests (Augmented Dickey-Fuller test (1979, 1981), Philips-Perron test (1992) and the KPSS test (1992)). The second class includes a unit root test which takes into account further structural break (Zivot and Andrews (1992)). Table 2 and 3 report the results for the four tests. According to the ADF and PP test statistics we reject the null hypothesis of a unit root at $1 \%$ significance level for all hedge funds indexes. The KPSS test statistics confirm the results of the ADF and PP test in acceptance of the hypothesis of stationarity at $1 \%$ significance level. However, these tests have low power when a break exists leading to a bias and this may affects the outcome of unit root tests. Leybourne and Newbold (2000) analyzed the effect of a break on a standard DF test and showed that size distortions can occur. Applying the procedure for testing the unit root hypothesis, which 
allows for the possible presence of the structural break, offers several advantages. It prevents yielding a test result which is biased towards non-rejection, as mentioned by Perron (1989). Second, since this procedure can identify when the possible presence of structural break occurred, then it would provide valuable information for analyzing whether a structural break is associated with a particular government policy, economic crises, war, regime shifts or other factors.

Table 2: Standard unit root tests

\begin{tabular}{|c|c|c|c|c|c|}
\hline \multirow[b]{2}{*}{ Series } & \multicolumn{2}{|c|}{$\mathrm{ADF}$} & \multicolumn{2}{|c|}{ PP } & \multirow{2}{*}{$\frac{\text { KPSS }}{\eta_{\mu}}$} \\
\hline & $\tau$ & $\tau_{\mu}$ & $Z_{t_{\alpha}}$ & $Z_{t_{\alpha}}$ & \\
\hline Hedge FundcIndex & $10.506^{-} * * *$ & $-11.424 * * *$ & $-10.841^{* * * *}$ & $-11.410 * * *$ & 0.146 \\
\hline Convertible Arbitrage & $-7.065 * * *$ & $-7.474 * * *$ & $-7.071^{* * *}$ & $-7.508 * * *$ & 0.079 \\
\hline Dedicated Short Bias & $12.838 * * *$ & $-12.856 * * *$ & $-12.766 * * *$ & $-12.789 * * *$ & 0.117 \\
\hline Emerging Markets & $10.314 * * *$ & $-10.422 * * *$ & $-10.328 * * *$ & $-10.461 * * *$ & 0.052 \\
\hline Equity Market Neutral & $13.308^{* * *}$ & $-13.431 * * *$ & $-13.441 * * *$ & $-13.531 * * *$ & $0.394 *$ \\
\hline Event Driven & $-6.102 * * *$ & $-9.778 * * *$ & $-9.070 * * *$ & $-10.019 * * *$ & 0.076 \\
\hline Fixed Incom Arbitrage & $-7.643 * * *$ & $-7.915 * * *$ & $-7.603 * * *$ & $-7.934 * * *$ & 0.086 \\
\hline Global Macro & $-3.895 * * *$ & $-12.938 * * *$ & $-12.185 * * *$ & $-12.943 * * *$ & 0.107 \\
\hline Long Short Equity & $10.868^{* * *}$ & $-11.537 * * *$ & $-11.006^{* * *}$ & $-11.564 * * *$ & 0.171 \\
\hline Managed Futures & $13.399 * * *$ & $-13.678^{* * *}$ & $-13.409 * * *$ & $-14.085^{* * *}$ & 0.039 \\
\hline Multi-Strategie & $-8.850 * * *$ & $-9.957 * * *$ & $-9.354 * * *$ & $-10.205^{* * *}$ & 0.086 \\
\hline
\end{tabular}

Therefore, we apply Zivot and Andrews (1992) unit root test which allows endogenous single structural break. This test is a sequential test which utilizes the full sample and uses a different dummy variable for each possible break date. The break date is selected where the t-statistic from the ADF test of unit root is at a minimum (most negative). Consequently a break date will be chosen where the evidence is least favorable for the unit root null. The results for model $\mathrm{C}$ and $\mathrm{A}$ of Zivot-Andrews unit root test are presented in table 3. These results suggest that we can reject the null hypothesis of unit root for all hedge funds indexes at $1 \%$ significance level. At the same time, the test identifies endogenously the point of the single most significant structural break in every time series examined in this paper. Table 3 indicates the estimated break date for each series: one relevant outcome is the coincidence between estimated break point and some historical facts, financial crisis precisely. The year 2008 may be considered as the most suitable candidate for a structural break in the CSFB/Tremont hedge fund indexes since it represents the subprime crisis. The result based on model A show that only four of the ten series studied bear witness of the presence of a structural break in this year: Convertible arbitrage ( September 2008), equity market neutral (January 2008), fixed- 
Table 3: Zivot-Andrews (1992) unit root test

\begin{tabular}{|c|c|c|c|c|c|c|c|}
\hline Series & $\hat{T}_{b}$ & $\hat{k}$ & $\hat{\mu}$ & $\hat{\theta}$ & $\hat{\beta}$ & $\hat{\gamma}$ & $\hat{\alpha}$ \\
\hline \multicolumn{8}{|c|}{ Modèle C : } \\
\hline Hedge FundcIndex & $1996: 01$ & 0 & $\begin{array}{r}-0.0194 \\
(-2.16)\end{array}$ & $\begin{array}{r}-0.0236 \\
(-2.61)\end{array}$ & $\begin{array}{r}0.0022 \\
(3.39)\end{array}$ & $\begin{array}{r}-0.0022 \\
(-3.44)\end{array}$ & $\begin{array}{l}-0.8371 \\
(-12.15)^{* * *}\end{array}$ \\
\hline Convertible Arbitrage & $2008: 10$ & 0 & $\begin{array}{r}0.0065 \\
(2.45)\end{array}$ & $\begin{array}{r}0.0241 \\
(3.09)\end{array}$ & $\begin{array}{l}0.0000 \\
(-1.91)\end{array}$ & $\begin{array}{c}-0.0008 \\
(-1.69)\end{array}$ & $\begin{array}{l}-0.5039 \\
(-8.31)^{* * *}\end{array}$ \\
\hline Dedicated Short Bias & $2009: 2$ & 0 & $\begin{array}{r}-0.0025 \\
(-0.35)\end{array}$ & $\begin{array}{r}-0.0394 \\
(-1.78)\end{array}$ & $\begin{array}{r}0.0000 \\
(0.38)\end{array}$ & $\begin{array}{r}0.0010 \\
(0.65)\end{array}$ & $\begin{array}{l}-0.9270 \\
(-13.16)^{* * * *}\end{array}$ \\
\hline Emerging Markets & $1997: 06$ & 6 & $\begin{array}{r}-0.0152 \\
(-1.06)\end{array}$ & $\begin{array}{r}-0.0399 \\
(-2.55)\end{array}$ & $\begin{array}{c}0.0014 \\
(2.10)\end{array}$ & $\begin{array}{c}-0.0014 \\
(-1.97)\end{array}$ & $\begin{array}{l}-0.7875 \\
(-5.40)^{* * *}\end{array}$ \\
\hline Equity Market Neutral & $2007: 12$ & 0 & $\begin{array}{r}0.0091 \\
(1.55)\end{array}$ & $\begin{array}{c}-0.0428 \\
(-3.00)\end{array}$ & $\begin{array}{l}0.0000 \\
(-0.20)\end{array}$ & $\begin{array}{r}0.0012 \\
(2.02)\end{array}$ & $\begin{array}{l}-1.0046 \\
(-14.21)^{\text {*** }}\end{array}$ \\
\hline Event Driven & $2007: 09$ & 0 & $\begin{array}{r}0.0051 \\
(1.96)\end{array}$ & $\begin{array}{r}-0.0191 \\
(-3.14)\end{array}$ & $\begin{array}{r}0.0000 \\
(0.58)\end{array}$ & $\begin{array}{r}0.0006 \\
(2.71)\end{array}$ & $\begin{array}{l}-0.6887 \\
(-10.42) * * *\end{array}$ \\
\hline Fixed Income Arbitrage & $1998: 09$ & 0 & $\begin{array}{c}0.0057 \\
(1.4)\end{array}$ & $\begin{array}{r}0.0078 \\
(1.67)\end{array}$ & $\begin{array}{r}-0.0002 \\
(-1.30)\end{array}$ & $\begin{array}{r}0.0001 \\
(1.03)\end{array}$ & $\begin{array}{l}-0.4778 \\
(-7.95)^{* * *}\end{array}$ \\
\hline Global Macro & $1998: 06$ & 5 & $\begin{array}{r}0.0103 \\
(1.30)\end{array}$ & $\begin{array}{r}-0.0285 \\
(-2.93)\end{array}$ & $\begin{array}{c}0.0004 \\
(1.54)\end{array}$ & $\begin{array}{c}-0.0004 \\
(-1.35)\end{array}$ & $\begin{array}{l}-1.0306 \\
(-6.33)^{* * * *}\end{array}$ \\
\hline Long Short Equity & $2000: 07$ & 4 & $\begin{array}{r}0.0058 \\
(0.90)\end{array}$ & $\begin{array}{r}-0.0269 \\
(-3.12)\end{array}$ & $\begin{array}{c}0.0003 \\
(1.98)\end{array}$ & $\begin{array}{c}-0.0002 \\
(-1.49)\end{array}$ & $\begin{array}{l}-1.1557 \\
(-8.01)^{* * * *}\end{array}$ \\
\hline Managed Futures & $1995: 12$ & 8 & $\begin{array}{r}0.0160 \\
(0.89)\end{array}$ & $\begin{array}{r}0.0375 \\
(2.12)\end{array}$ & $\begin{array}{c}-0.0025 \\
(-1.42)\end{array}$ & $\begin{array}{r}0.0025 \\
(1.41)\end{array}$ & $\begin{array}{l}-1.5751 \\
(-5.28)^{* * *}\end{array}$ \\
\hline Multi-Strategy & $2008: 4$ & 0 & $\begin{array}{c}0.0061 \\
(2.80) \\
\end{array}$ & $\begin{array}{c}-0.0725 \\
(-4.8)\end{array}$ & $\begin{array}{l}0.0000 \\
(-0.60) \\
\end{array}$ & $\begin{array}{c}0.0004 \\
(1.32) \\
\end{array}$ & $\begin{array}{c}-0.7105 \\
(-10.9) \\
\end{array}$ \\
\hline \multicolumn{8}{|c|}{ Modèle A : $y_{t}=\mu^{A}+\theta^{A} D U \quad \lambda_{t}+\beta^{A} t+\alpha^{A} y_{t-1}+\sum^{k} c_{j}{ }_{j}^{A} y_{t-j}+\varepsilon_{t}$} \\
\hline Hedge FundcIndex & $2000: 01$ & 0 & $\begin{array}{r}0.0077 \\
(2.47)\end{array}$ & $\begin{array}{l}-0.0097 \\
(-1.7112)\end{array}$ & $\begin{array}{c}0.0000 \\
(0.95)\end{array}$ & & $\begin{array}{l}-0.7998 \\
(-11.60)^{* * * *}\end{array}$ \\
\hline Convertible Arbitrage & $2008: 09$ & 0 & $\begin{array}{r}0.0070 \\
(2.67)\end{array}$ & $\begin{array}{l}0.0157 \\
(3.5974)\end{array}$ & $\begin{array}{r}-0.0001 \\
(-2.35)\end{array}$ & & $\begin{array}{l}-0.4699 \\
(-8.17)^{* * *}\end{array}$ \\
\hline Dedicated Short Bias & $2009: 01$ & 0 & $\begin{array}{r}-0.0027 \\
(-0.37)\end{array}$ & $\begin{array}{l}-0.0278 \\
(-2.1581)\end{array}$ & $\begin{array}{r}0.0000 \\
(0.41)\end{array}$ & & $\begin{array}{l}-0.9267 \\
(-13.17)^{* * * *}\end{array}$ \\
\hline Emerging Markets & $1999: 01$ & 6 & $\begin{array}{r}0.0008 \\
(0.12)\end{array}$ & $\begin{array}{l}0.0181 \\
(1.6907)\end{array}$ & $\begin{array}{r}-0.0001 \\
(-1.10)\end{array}$ & & $\begin{array}{l}-0.7330 \\
(-5.09) * * *\end{array}$ \\
\hline Equity Market Neutral & $2008: 01$ & 0 & $\begin{array}{r}0.0079 \\
(1.35)\end{array}$ & $\begin{array}{l}-0.0220 \\
(-2.3435)\end{array}$ & $\begin{array}{r}0.0000 \\
(0.00)\end{array}$ & & $\begin{array}{l}-0.9912 \\
(-14.00)^{* * *}\end{array}$ \\
\hline Event Driven & $2009: 02$ & 0 & $\begin{array}{r}0.0076 \\
(2.92)\end{array}$ & $\begin{array}{l}0.0083 \\
(1.8514)\end{array}$ & $\begin{array}{r}0.0000 \\
(-1.30)\end{array}$ & & $\begin{array}{l}-0.6598 \\
(-9.98)^{* * *}\end{array}$ \\
\hline Fixed Income Arbitrage & $2008: 12$ & 1 & $\begin{array}{r}0.0067 \\
(2.87)\end{array}$ & $\begin{array}{l}0.0131 \\
(3.1829)\end{array}$ & $\begin{array}{r}-0.0001 \\
(-2.43)\end{array}$ & & $\begin{array}{l}-0.6037 \\
(-8.48)^{* * *}\end{array}$ \\
\hline Global Macro & $1998: 06$ & 5 & $\begin{array}{r}0.0187 \\
(3.85)\end{array}$ & $\begin{array}{l}-0.0195 \\
(-2.7490)\end{array}$ & $\begin{array}{r}0.0001 \\
(1.20)\end{array}$ & & $\begin{array}{l}-0.9666 \\
(-6.19) * * *\end{array}$ \\
\hline Long Short Equity & $2000: 01$ & 5 & $\begin{array}{r}0.0132 \\
(3.07)\end{array}$ & $\begin{array}{l}-0.0232 \\
(-3.1742)\end{array}$ & $\begin{array}{r}0.0001 \\
(1.76)\end{array}$ & & $\begin{array}{l}-0.9557 \\
(-6.32)^{* * *}\end{array}$ \\
\hline Managed Futures & $2000: 09$ & 8 & $\begin{array}{c}0.0063 \\
(1.24)\end{array}$ & $\begin{array}{c}0.0169 \\
(1.8007)\end{array}$ & $\begin{array}{c}-0.0001 \\
(-1.23)\end{array}$ & & $\begin{array}{l}-1.4879 \\
(-5.19)^{* * * *}\end{array}$ \\
\hline Multi-Strategy & $2008: 04$ & 0 & $\begin{array}{c}0.0058 \\
(2.65)\end{array}$ & $\begin{array}{c}0.0021 \\
(0.58)\end{array}$ & $\begin{array}{l}0.0000 \\
(-0.49)\end{array}$ & & $\begin{array}{l}-0.6867 \\
(-11.02)^{* * *}\end{array}$ \\
\hline
\end{tabular}

Note: The student's t-statistics are in parentheses. The t-statistics for $\hat{\alpha}^{j}$ is for testing $\alpha^{j}=1$. The critical values at the $10 \%, 5 \%$ and $1 \%$ significance level for model C (resp. model A) are: $-4.82,-5.08$ and $-5.34(-4.11,-4.42$ and -4.58$)$. *, ** and *** denote significance at the $10 \%, 5 \%$ and $1 \%$ levels.

income arbitrage (December 2008) and multi-strategy (April 2008). The break point occurs few months later for dedicated short bias (January 2009) and even driven (February 2009). 
Contrary to prevailing perception, the year 2000 emerges for three series also: hedge fund index (January 2000), long-short equity (February 2000) and managed futures (September 2000). The IT bubble in 2000 may be considered as the most suitable fact for these breaks. The break date for the global macro strategy may be attributed to the Russian crisis of 1998 . The estimated break points from model $\mathrm{A}$ and $\mathrm{C}$ suggest that the CSFB/Tremont hedge fund indexes are subject to more than one structural break.

\subsection{Fractional integration :}

We propose to estimate the level of persistence for each series using several methods. We employ the Hurst exponent estimated using the rescaled range statistic (R/S) introduced by Hurst (1951) and wavelet-based estimator of Abry and Veitch (1998). According to Koh et al. (2005), A Hurst exponent between 0 and 0.5 means that a manager's return are "antipersistent" and will tend to fluctuate randomly, but converge to a stable value over time. With a Hurst exponent of about 0.5, a hedge fund manager's track performance will be regarded as random, so that returns in one period will not be affected by returns in another period. Such hedge funds are deemed to be risky because any stellar short-term gains may be accompanied by substantial losses in another time period. A Hurst coeficient between 0.5 and 1 describes returns that are persistent. These fund managers have "hot" hands.

Table 4. Estimates of the long memory parameters for the CSFB/Tremont hedge fund indexes.

\begin{tabular}{|c|c|c|c|c|c|}
\hline Series & $\hat{H}$ & $\hat{H}_{A V}$ & $\hat{d}_{G P H}$ & $\hat{d}_{G S P}$ & $\hat{d}_{M L}$ \\
\hline Hedge FundcIndex & 0.571 & $\begin{array}{c}0,597 \\
0,378: 0,815\end{array}$ & $\begin{array}{l}0,19 * * \\
0,0337\end{array}$ & $\begin{array}{l}0,19 * * * \\
0,0017\end{array}$ & $\begin{array}{l}0,22 \text { *** } \\
0,0000\end{array}$ \\
\hline Convertible Arbitrage & 0.628 & $\begin{array}{c}0,948 \\
{[0,730: 1,167]}\end{array}$ & $\begin{array}{l}0,39 * * * \\
0,0000\end{array}$ & $\begin{array}{l}0,42 \text { *** } \\
0,0000\end{array}$ & $\begin{array}{l}0,45^{* * *} \\
0,0000\end{array}$ \\
\hline Dedicated Short Bias & 0.482 & $\begin{array}{c}0,695 \\
0,477: 0,913\end{array}$ & $\begin{array}{c}-0,08 \\
{[0,3859]}\end{array}$ & $\begin{array}{c}-0,03 \\
0,5971\end{array}$ & $\begin{array}{l}0,03 \\
0,6940\end{array}$ \\
\hline Emerging Markets & 0.522 & $\begin{array}{c}0,662 \\
0,444: 0,881\end{array}$ & $\begin{array}{l}0,10 \\
0,2526\end{array}$ & $\begin{array}{l}0,16 * * * \\
0,0073\end{array}$ & $\begin{array}{l}0,23 * * * \\
0,0000\end{array}$ \\
\hline Equity Market Neutral & 0.550 & $\begin{array}{c}0,075 \\
-0,101: 0,251\end{array}$ & $\begin{array}{l}0,08 \\
0,3849\end{array}$ & $\begin{array}{l}0,07 \\
0,2691\end{array}$ & $\begin{array}{l}0,08 \\
0.1200\end{array}$ \\
\hline Event Driven & 0.560 & $\begin{array}{c}0,885 \\
0,686: 1,085\end{array}$ & $\begin{array}{l}0,28 * * * \\
0,0019\end{array}$ & $\begin{array}{l}0,31^{* * *} \\
0,0000\end{array}$ & $\begin{array}{l}0,33^{\star * *} \\
0,0000\end{array}$ \\
\hline Fixed Income Arbitrage & 0.602 & $\begin{array}{c}0,676 \\
0,458: 0,894\end{array}$ & $\begin{array}{l}0,33 * * * \\
0,0002\end{array}$ & $\begin{array}{l}0,32 * * * \\
0,0000\end{array}$ & $\begin{array}{l}0,42 \\
0,0000\end{array}$ \\
\hline Global Macro & 0.575 & $\begin{array}{c}0,656 \\
0,437: 0,874\end{array}$ & $\begin{array}{l}0,23^{\star *} \\
0,0111\end{array}$ & $\begin{array}{l}0,15^{* * *} \\
0,0098\end{array}$ & $\begin{array}{l}0,16^{* * *} \\
0,0000\end{array}$ \\
\hline Long Short Equity & 0.609 & $\begin{array}{c}0,7 \\
0,482: 0,918\end{array}$ & $\begin{array}{l}0,14 \\
0,1228\end{array}$ & $\begin{array}{l}0,12 \text { ** } \\
0,0436\end{array}$ & $\begin{array}{l}0,19 * * * \\
0,0000\end{array}$ \\
\hline Managed Futures & 0.426 & $\begin{array}{c}0,588 \\
0,412: 0,764\end{array}$ & $\begin{array}{c}-0,22 \text { ** } \\
{[0,029]}\end{array}$ & $\begin{array}{l}-0,18 \text { ***} \\
0,0027\end{array}$ & $\begin{array}{l}0,01 \\
0,8620\end{array}$ \\
\hline Multi-Strategy & 0.597 & $\begin{array}{c}0.853 \\
0.676: 1.029 \\
\end{array}$ & $\begin{array}{l}0.36 \text { *** } \\
0.0002\end{array}$ & $\begin{array}{l}0.33^{\star * *} \\
0.0000\end{array}$ & $\frac{0.30}{0.000}$ \\
\hline
\end{tabular}

Note: The p-values are indicated between brackets. ***, $* *$ and $*$ denote significance at $1 \%, 5 \%$ and $10 \%$ level respectively. 
The estimated Hurst exponent based on the R/S method, reported in table 4, shows that nine of the $11 \mathrm{CSFB} /$ Tremont hedge fund indexes are persistent. Two series (Dedicated Short Bias and Managed Futures) exhibit anti-persistence behavior. Their estimated Hurst coefficients are less than 0.5. These results confirm those of Amenc et al (2003) for all investment style. The Hurst exponent is a useful tool to evaluate performance persistence. However this estimate is biased when long-range dependence is absent and its distribution is unknown so that we can't test its statistical significance. Therefore, we consider the wavelet-based estimator of Abry and Veitch (1998) using Daubechies2 wavelet. Abry and Veitch (1998) showed that the waveled-based estimator is consistent and allow the detection of deterministic trends in order to avoid their adverse effects on the estimation of $H$. Wavelet-based estimators confirm latter results since most coefficients are greater than 0.5 and significant except for equity market neutral $(0.075)$ where zero lies within the confidence interval.

Hurst exponent is related to the long memory parameter $d$ i.e. fractional integration parameter by the equation $d=H-1 / 2$. Henceforth, we employ three methods to estimate $d$ : the maximum likelihood method, the log-periodogram regression method of Geweke and PorterHudak (1983) and the Gaussian semiparametric estimator of Robinson (1995). Concerning the estimation of the long memory parameter, semiparametric estimates require the determination of bandwidths i.e number of frequency to include in regression: for GPH (1983) we chose $T^{0.6}$ and for Robinson (1995) we chose $T^{0.7}: \hat{d}_{G P H}$ ranges from -0.22 to 0.39 and $\hat{d}_{G S P}$ ranges from -0.18 to 0.42 . The results, also reported in table 4 , show evidence that a long memory component is present in all series except dedicated short bias and equity market neutral. The fractional parameters estimated by the maximum likelihood method confirm the fractional behavior of the studied series since $\hat{d}_{M L}$ ranges from 0.01 to 0.42 . However, the estimated parameters for dedicated short bias and equity market neutral are not significant.

In general, six of the studied series show clear evidence of fractional integration: Hedge Fund Index, Convertible Arbitrage, Event Driven, Fixed Income Arbitrage, Global Macro and Multi-Strategy. The other results are mitigated and depend on the method employed to estimate the parameter. Combining these results with those of unit root tests with structural break, lead us to raise several questions concerning break inference and whether the observed long memory component is a true or spurious one.

\subsection{Long memory validation:}

A slow regime switching models or structural breaks can generate a strong persistence in the autocorrelation function and generate "spurious long memory" (Diebold and Inoue (2001), Granger and Hyung (2004)). This means that the observed long memory characteristics can be confused with structural breaks. In order to distinguish between the two phenomenons and to detect the influence of structural breaks on fractional parameters, we will employ two recent tests of Shimotsu (2006). Shimotsu (2006) proposes two tests of true versus spurious long memory. The first test is based on the fact that if a time series is fractionally integrated i.e $\mathrm{I}(\mathrm{d})$ process, then each subsample of the time series is also fractionally integrated with the same value of $d$. In the first stage, we split each series into b subsamples ${ }^{8}$, we estimate $d$ using two

\footnotetext{
${ }^{8}$ So that each sample has $n / b$ observations and assuming $n / b$ is integer.
} 
step feasible exact local whittle estimator (FELW) of Shimotsu (2006), and we compare them with the estimate of $d$ from the full sample:

$$
H_{0}: d_{0}=d_{0,1}=\ldots=d_{0, b}
$$

Where $d_{0, a}$ is the true value of $\mathrm{d}$ from the ath subsample. For spurious $\mathrm{I}(\mathrm{d})$ models, the averaged estimates from subsamples tend to differ from the full sample estimate, and their difference increases as the degree of sample splitting increases. Formally, Shimotsu introduces the adjusted Wald statistic for testing true I(d) versus spurious I(d) :

$$
W_{c}=4 m\left(c_{m / b} /(m / b)\right) A \hat{d}_{b} A \Omega A^{\prime}+A \hat{d}_{b}^{\prime}
$$

Where $c_{m}=\sum_{j=1}^{m} v_{j}^{2}, v_{j}=\log j-\frac{1}{m} \sum_{j=1}^{m} \log j$.

Shimotsu showed also that $W, W_{c} \rightarrow_{d} \chi^{2}(b-1)$ as $n \rightarrow \infty$.

The second test of Shimotsu is based on the fact that, if a time series follows an I(d) process, then its $d$ th differenced series follow an $I(0)$ process: we estimate $\mathrm{d}$ on the whole sample and we use the estimate to take the $d$ th difference of the sample :

$$
\hat{u}_{t}=(1-L)^{\hat{d}}\left(X_{t}-\hat{\mu}(\hat{d})\right)=\sum_{k=0}^{t-1} \frac{\Gamma(-\hat{d}+k)}{\Gamma(-\hat{d}) k !}\left(X_{t-k}-\hat{\mu}(\hat{d})\right)
$$

After regression, we apply the KPSS test and PP unit root tests to the differenced data and its

\begin{tabular}{|c|c|c|c|c|c|c|c|}
\hline \multirow[b]{2}{*}{ Series } & \multirow{2}{*}{$\hat{d}_{f e l w}$} & \multicolumn{2}{|c|}{$\bar{d}$} & \multicolumn{2}{|c|}{$W_{c}$} & \multirow[b]{2}{*}{$Z_{t}$} & \multirow[b]{2}{*}{$\hat{\eta}_{\mu}$} \\
\hline & & $\mathrm{b}=2$ & $\mathrm{~b}=3$ & $\mathrm{~b}=2$ & $\mathrm{~b}=3$ & & \\
\hline Hedge FundcIndex & 0.213 & 0.278 & 0.295 & 2.201 & 1.729 & -2.601 & 0.059 \\
\hline Convertible Arbitrage & 0.450 & 0.558 & 0.596 & 2.053 & 1.825 & $-3.312 *$ & 0.029 \\
\hline Dedicated Short Bias & -0.011 & -0.008 & 0.047 & 0.333 & 1.790 & $-3.061 *$ & 0.118 \\
\hline Emerging Markets & 0.205 & 0.261 & 0.277 & 0.714 & 0.558 & $-3.093 *$ & 0.035 \\
\hline Equity Market Neutral & 0.126 & 0.222 & 0.288 & 2.082 & 2.249 & -1.645 & 0.239 \\
\hline Event Driven & 0.372 & 0.397 & 0.412 & 0.354 & 0.605 & $-3.493 *$ & 0.027 \\
\hline Fixed Income Arbitrage & 0.319 & 0.338 & 0.219 & 0.084 & $8.847^{*}$ & -2.997 & 0.033 \\
\hline Global Macro & 0.135 & 0.152 & 0.220 & 0.130 & 0.064 & -2.609 & 0.066 \\
\hline Long Short Equity & 0.194 & 0.235 & 0.253 & 0.834 & 0.687 & -2.337 & 0.072 \\
\hline Managed Futures & -0.180 & -0.216 & -0.133 & 3.180 & 3.951 & -2.756 & 0.051 \\
\hline Multi-Strategy & 0.379 & 0.335 & 0.311 & $5.377 *$ & 5.701 & $-3.392 *$ & 0.0297 \\
\hline
\end{tabular}
partial sum.

Table 5. Estimation and test results of Shimotsu (2006)

Note :* indicates rejection of the null hypothesis at the 5\% level. $\chi_{0.95}^{2}(1)=3,84, \chi_{0.95}^{2}(2)=5,99$.

Table 5 reports the estimates of $\hat{d}$ using the two step feasible exact local whittle method of Shimotsu and Philips $(2005,2010), \bar{d}, W_{c}, Z_{t}$ and $\hat{\eta}_{\mu}$ for the CSFBT/Tremont hedge fund indices for $m=60$ and $b=2,3$.The estimated values of $\hat{d}$ and $\bar{d}$ are close to each other, 
and the $W_{c}$ test rejects the null of constancy of $\mathrm{d}$ for Multi-Strategy for $\mathrm{b}=2$ and for Fixed Income Arbitrage for $\mathrm{b}=3 . \hat{\eta}_{\mu}$ statistic do not reject the null of $I \hat{d}$ in most cases. However, $Z_{t}$ statistic rejects the null hypothesis for four series (Convertible Arbitrage, Dedicated Short Bias, Emerging Markets and Event Driven). This suggests a possibility of a Markov switching model. According to Shimotsu (2006), $Z_{t}$ test has very strong power against the Markov switching model. We employed several tests to distinguish between true and spurious long memory. The results in table 5 do not reveal strong evidence against true $\mathrm{I}(\mathrm{d})$, even though shifts and or structural breaks are present. These results confirm those of Granger and Hyung (2004), Zivot and Choi (2005) and Shimotsu (2006) in a sense that a pure I(d) process may not explain all of the persistence of a time series, but the data do not support an extreme view that structural breaks account for all the observed persistence. However, as mentioned by Levancier et al. (2013) Shimotsu's test may be employed to detect non-constant long memory parameter. In this approach, the rejection of the null may be due to a change in the level of persistence. In view of this evidence, we employ the MS-ARFIMA formulation which combines both Markov Switching models and long memory in each state to explore the dynamics of the CSFBT/Tremont hedge fund indices.

\subsection{MS-ARFIMA Model}

The MS-ARFIMA(p,d,q) model of Tsay and Härdle (2009) takes into account two important characteristics of financial time series: long memory and persistence through the fractional integration parameters and shifts through Markov regime switch. Formally, we consider that the CSFB/Tremont hedge funds indexes can me modelled using two state MS$\operatorname{ARFIMA}(1, \mathrm{~d}, 1)$ model across different specifications:

$$
\begin{gathered}
w_{t}=\mu_{S_{t}} I t \geq 1+1-L^{d_{S_{t}}} \sigma_{S_{t}} z_{t} I t \geq 1 \\
\left(1-\phi_{1} L\right) z_{t}=1-\theta_{1} L \varepsilon_{t}
\end{gathered}
$$

Table 7 shows the estimated parameters generated from the Durbin-Levinson-Viterbi (DLV) algorithm developed by Tsay and Härdle (2009): long memory parameters ( $d_{1}$ and $d_{2}$ ) for each regime, the probability of remaining in the current regime, knowing that this regime was in place in the immediately previous period $\left(p_{11}\right.$ and $\left.p_{22}\right)$, standard deviations of hedge fund returns $\left(\sigma_{1}\right.$ and $\left.\sigma_{2}\right)$ and their associated means $\left(\mu_{1}\right.$ and $\left.\mu_{2}\right)$. It also includes autoregressive and moving average parameters which depend on the specification chosen for each series. Most estimated parameters are statistically significant at 5\% level and their values reveal that the CSFB/Tremont hedge fund indexes yields evidence of asymmetrical and time varying adjustment.

The estimates of $\sigma_{1}$ and $\sigma_{2}$ in Table 7 show that the volatility of hedge fund returns in the first regime is higher than the volatility of second regime. In what follows, we consider the markovian chain $S=1$ as the high-volatility regime and $S=2$ as the low-volatility regime. 
The mean $\left(\mu_{1}\right)$ associated to high volatility regime is negative and significant for most of the studied series (Convertible Arbitrage, Emerging Markets, Equity Market Neutral, Equity Market Neutral and Multi-Strategy) and when its estimated value is positive, statistically, it's not different from zero. Mean levels $\left(\mu_{2}\right)$ are positive and statistically significant. Except of Hedge Fund general Index which present different characteristics from other series, and compared to the second regime, the first one yields lower mean levels $\left(\mu_{1}<\mu_{2}\right)$. In summary, we found that $\sigma_{1}>\sigma_{2}$ and $\mu_{1}<\mu_{2}$. We also observe that that the value of $p_{22}$ is larger than the value of $p_{11}$ which means that the probability to stay in the second regime is higher than that of the first regime.

Table 7. Estimates of MS-ARFIMA(p,d,q) model for the CSFB/Tremont hedge fund indexes.

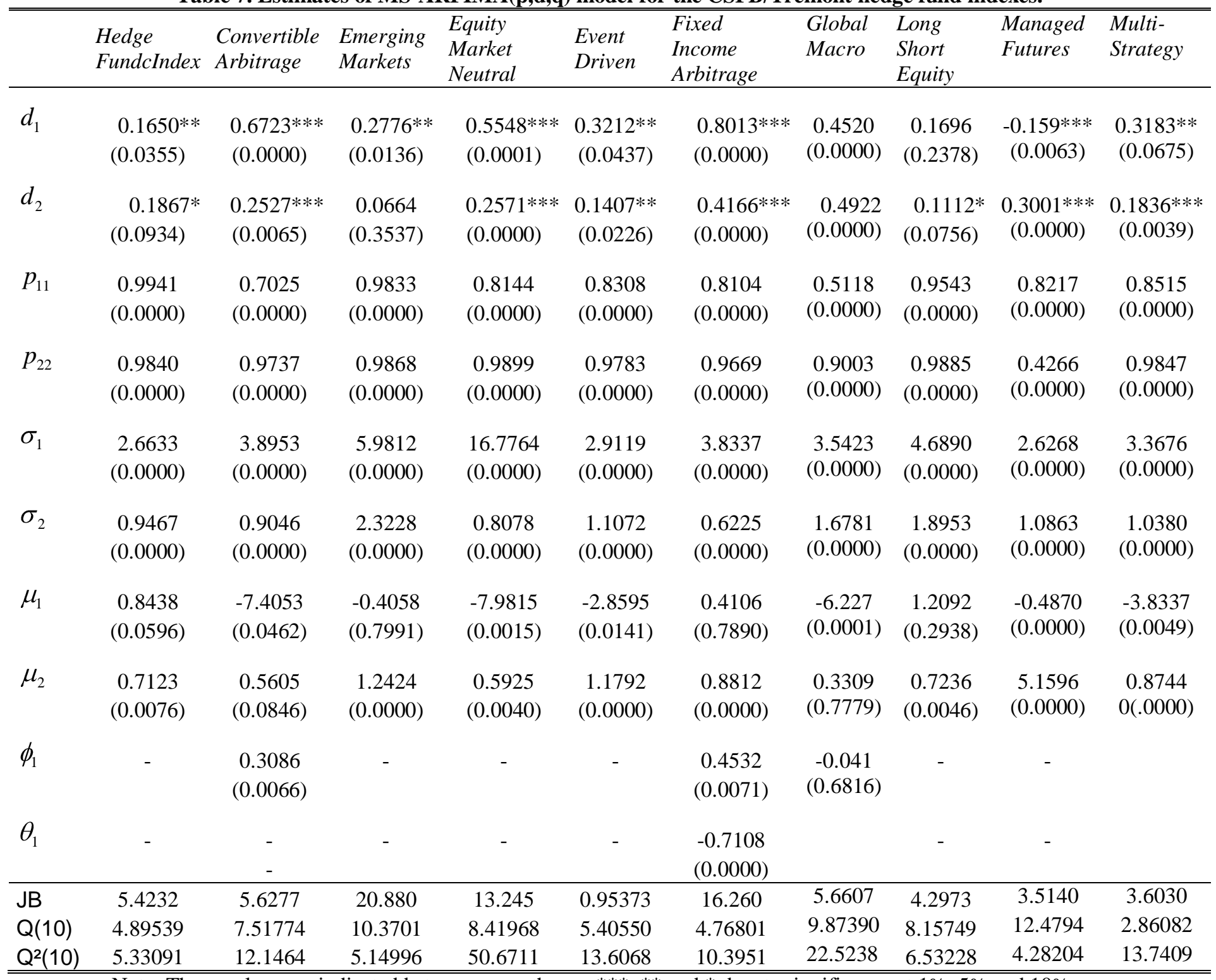

Note: The p-values are indicated between parentheses. ***, ** and * denote significance at $1 \%, 5 \%$ and $10 \%$ level respectively. 
Henceforth, our methodology is not only motivated by the markovian dynamics of hedge fund returns but also by their related memory and fractional integration behavior. The estimates of $d_{1}$ and $d_{2}$ show that the CSFB/Tremont indexes are also characterized by two levels of persistence. In general, (Except for Hedge Fund Index, Global Macro and Managed Futures), we found that $d_{1}>d_{2}$ which implies that the memory and shock persistence is stronger in high-volatility regime. The fractional integration parameters for high-volatility regime range from -0.159 to 0.8013 , while those of low volatility regime range from 0.0664 to 0.4166 . In low-volatility state, hedge fund returns exhibit high persistence and their associated dynamics is governed by a long memory component. This means that shock effects on returns will persist for a long time and that they converge slowly to a steady state. Concerning the highvolatility regime, result interpretation is quite different and varies with the considered strategy. For Managed Futures, estimated fractional integration parameter is equal to -0.159 indicating that in high volatility regime this strategy exhibits an intermediate memory or antipersistence. Three of the considered series (Convertible Arbitrage, Equity Market Neutral and Fixed Income Arbitrage) display a non-stationary but mean-reverting behavior since their estimated long memory parameter ranges from 0.55 to 0.8 . In this case, this implies even though remote shocks affect the present value of the series, this will tend to the value of its mean in the long run.

Table 8. Memory behavior of CSFB/Tremont hedge fund indexes under the low and high-volatility regimes

\begin{tabular}{lcccccc}
\hline \hline \multirow{2}{*}{ Indices } & \multicolumn{7}{c}{ High-volatility regime } & \multicolumn{4}{c}{ Low-volatility regime } & \\
\cline { 2 - 6 } & $\mu_{1}$ & $\sigma_{1}$ & $d_{1}$ & $\mu_{2}$ & $\sigma_{2}$ & $d_{2}$ \\
\hline Convertible Arbitrage & $-7,41$ & 3,90 & 0,67 & 0,56 & 0,90 & 0,25 \\
Emerging Markets & $-0,41$ & 5,98 & 0,27 & 1,24 & 2,32 & 0,07 \\
Equity Market Neutral & $-7,98$ & 16,78 & 0,55 & 0,59 & 0,81 & 0,26 \\
Event Driven & $-2,86$ & 2,91 & 0,32 & 1,18 & 1,11 & 0,14 \\
Fixed Income Arbitrage & $0,41 * * *$ & 3,83 & 0,8 & 0,88 & 0,62 & 0,42 \\
Global Macro & -6.227 & 3.54 & 0.45 & $0.33 * * *$ & 1.67 & 0.49 \\
Long Short Equity & $1,21 * * *$ & 4,69 & 0,17 & 0,72 & 1,90 & 0,11 \\
Managed Futures & -0.48 & 2.62 & -0.15 & 5.15 & 2.62 & 0.30 \\
Multi-Strategy & -3.83 & 3.36 & 0.31 & 0.87 & 1.03 & 0.18 \\
\hline Note: *** statistically not different from zero $1 \%$ level. & & & & &
\end{tabular}

Table 8 summarizes the characteristics of each regime and figure $2 \mathrm{a}$ to $2 \mathrm{j}$ display the path of the estimated long memory parameters for each series. Not surprisingly, we find coincidence between transition dates and structural break detected in previous section; also, the high volatility states of the CSFB/Tremont indexes are associated with crisis periods. However, most impressively, the magnitude of $d$ shows the effect of memory and shock persistence on the considered series: greater is the long memory parameter, stronger is the memory and 
shock persistence. The high-volatility regime exhibits higher parameter of fractional integration than those of the low-volatility regime. More precisely, the process tends to be non-stationary and exhibits a mean-reverting behavior in periods of turmoil. The latter result proves the importance of persistence and memory phenomenon associated with hedge fund adjustments. The MSARFIMA model adjusts well hedge fund return dynamics by taking into account time varying parameter, asymmetry and memory phenomenon. Table 7 presents also results for the Jarque-Bera normality tests. It asserts that normality is accepted for 7 out of 10 series. This finding reveals the importance of introducing fractional integration inside each regime and indicates that the MSARFIMA modeling can supplant traditional hedge fund returns modeling.

\subsection{Forecasting analysis}

At this stage, we evaluate the performance of the Markov Switching, ARFIMA and MSARFIMA models to forecast in-sample and out-of-sample hedge fund returns. In the out-ofsample analysis, we consider the period starting February 2011 and ending January 2012 for a total of 12 months. In the case of the standard MS model we consider Monte Carlo simulation. Following Davidson (2004, 2005), we perform 1000 replications and extract the median estimate of return forecasts. Forecasts from the MS-ARFIMA model are expressed as the sum of the conditional forecasts, i.e forecast from the two different ARFIMA specification inside each regime, weighted by the probability of being in that state.

Table 9 reports the root mean squared errors (RMSE) for each series. Concerning in-sample analysis, the RMSE of the MS-ARFIMA model are lower than that of the MS and the ARFIMA models. This result highlights the ability of the combined model to fit the dynamics of hedge fund returns. In addition, differences between the actual and the fitted series show that the RMSE of the MS model are marginally lower than the ARFIMA model. MS models are also successful specification to approximate the characteristics of hedge fund returns. Concerning the out-of-sample analysis, table 9 indicates that allowing for long memory leads to better forecasts. Forecasts generated from the MSARFIMA and ARFIMA model are almost superior to those of the MS model since these models presents the lowest RMSE. Henceforth, according to Bawens and Sucarrat (2010) the use of the RMSE can be considered as weakness since it's a "pure" precision measures, in the sense that the evaluation is based solely on the discrepancy between the forecast and the actual value.

In order to check the predictive power of the MSARFIMA model against the two other models, we employ Hansen's (2005) superior predictive ability test (SPA test). In this test, forecasts are evaluated using a pre-specified loss function, and the forecast model that generates the smallest expected loss is regarded to be the best-performing one. It compares the forecasting performance of a benchmark model against its $\mathrm{m}$ competitors. Under the null hypothesis, the benchmark model is not outperformed by competing model $k$, for $k=1, \ldots, m$. Following Hansen (2005) notation, let $d_{k, t}$ denotes the performance of model k relative to the benchmark at time t: 


$$
d_{k, t} \equiv L \xi_{t}, \delta_{0, t-h}-L \xi_{t}, \delta_{k, t-h}
$$

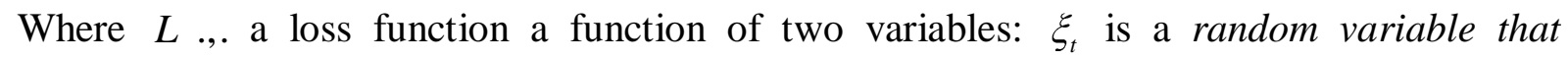
represents the aspects of the decision problem that are unknown at the time that the decision is made, and $\delta_{k, t-h}$ represents a possible decision rule which is made heriods in advance.

The SPA studentized test statistic is given by:

$$
T_{n}^{S P A}=\max \left[\max _{k=1 \ldots m} \frac{n^{1 / 2} \bar{d}_{k}}{\hat{\omega}_{k}}, 0\right]
$$

Where $\bar{d}_{k}$ is the $\mathrm{k}$-th element of $\bar{d}=n^{-1} \sum_{t=1}^{n} d_{t}$ and $\hat{\omega}_{k}^{2}$ is a consistent estimator of $\omega_{k}^{2}=\operatorname{var} n^{1 / 2} \bar{d}_{k}$.

We conduct the SPA test using 10000 bootstraps and dependence parameter q equal to 0.5 . We specify the mean squared error (MSE) as loss function for models evaluation while considering the MSARFIMA model as a benchmark. Table 9 reports the p-values of the tests for SPA. A high p-value indicates evidence in support of the hypothesis that the benchmark model is superior to one or more of the rival models. As the p-value of the test is higher than 0.1 for all series, it appears that there is evidence supporting the hypothesis that the forecasting ability of the MSARFIMA model is superior to its two other competitors.

Table 9. In and Out-of-sample specification tests

\begin{tabular}{lccc|cccc} 
& \multicolumn{3}{c}{ In-Sample } & \multicolumn{3}{c}{ Out-of-Sample } \\
\cline { 2 - 7 } & MS & ARFIMA & MSARFIMA & MS & ARFIMA & MSARFIMA & SPA \\
\hline \hline Hedge FundcIndex & 2.2021 & 2.1747 & $\mathbf{0 . 9 9 7 5 6}$ & 1.8750 & 1.7424 & $\mathbf{1 . 6 9 9 4}$ & 0.5111 \\
Convertible Arbitrage & 1.9140 & 1.7861 & $\mathbf{0 . 9 9 7 5 5 6}$ & 1.5008 & 1.6166 & $\mathbf{1 . 4 5 2 3}$ & 0.5983 \\
Dedicated Short Bias & $\mathbf{3 . 6 7 9 7}$ & 4.8535 & & 5.0686 & 5.0801 & & \\
Emerging Markets & 4.3569 & 4.3137 & $\mathbf{0 . 9 9 7 5 5 5}$ & 3.3937 & $\mathbf{3 . 2 1 3 3}$ & 3.3087 & 0.1457 \\
Equity Market Neutral & 2.8460 & 3.8080 & $\mathbf{0 . 9 9 7 5 5 6}$ & 1.4984 & 1.4922 & $\mathbf{1 . 4 7 8 1}$ & 0.6076 \\
Event Driven & 1.4051 & 1.6810 & $\mathbf{0 . 9 9 8 0 7 9}$ & 2.9959 & 2.9658 & $\mathbf{2 . 9 5 2 4}$ & 0.7655 \\
Fixed Income Arbitrage & 1.5343 & 1.5666 & $\mathbf{0 . 9 9 7 5 5 5}$ & 0.4837 & 0.6285 & $\mathbf{0 . 4 6 4 9}$ & 0.6466 \\
Global Macro & 2.8624 & 2.8907 & $\mathbf{0 . 9 9 7 5 5 9}$ & 1.1695 & 1.1619 & $\mathbf{1 . 1 3 3 9}$ & 0.5703 \\
Long Short Equity & 2.8469 & 2.8245 & $\mathbf{0 . 9 9 7 5 5 3}$ & 3.0446 & $\mathbf{2 . 9 2 4 8}$ & 3.0327 & 0.9203 \\
Managed Futures & 2.7369 & 3.4178 & $\mathbf{1 . 0 1 5 8 1 7}$ & 3.2131 & $\mathbf{3 . 1 3 3 0}$ & 3.2113 & 0.3775 \\
Multi-Strategy & 1.3770 & 1.4895 & $\mathbf{0 . 9 9 9 9 5 1}$ & 1.5293 & $\mathbf{1 . 4 7 9 3}$ & 1.5570 & 0.1512 \\
\hline \hline
\end{tabular}




\section{Conclusion:}

Several studies have demonstrated the time varying properties of hedge fund return dynamics. However, limited literature has focused on hedge fund dynamics and persistence phenomenon in a unified framework. Our contribution to the current literature consists on establishing a relationship between memory phenomenon (persistence) and time varying properties of hedge fund dynamics.

Empirically, we examine the dynamics of the CSFB/Tremont hedge fund indexes monthly data starting January 1994 and ending January 2012 and their associated behavior of persistence in a unified framework through the MS-ARFIMA model of Härdle and Tsay (2009). This model accommodates both persistence through fractional integration and regime switching. Major results show that The CSFB/Tremont hedge funds indexes are characterized by two levels of persistence: we identify a first regime in which the volatility is relatively low. In this regime, the studied series display positive returns and exhibit persistence. Concerning the second regime, the volatility is relatively high. Mean returns associated to this regime are either negative or stastically not different from zero.

Most impressively, our findings enable us to establish a relationship between hedge fund states and memory phenomenon. In general, the high-volatility regime exhibits higher parameter of fractional integration than those of the low-volatility regime. More precisely, the process tends to be non-stationary and exhibits a mean-reverting behavior in periods of turmoil. This result proves the importance of persistence and memory phenomenon associated with hedge fund adjustments. We also find that the identified regimes are clearly aligned with financial events. Our results show that the two-state MS-ARFIMA model is better than Markov switching and ARFIMA models, when employed separately, in fitting the dynamics of the ex post hedge fund returns since normality is accepted for 7 out of 10 modeled series.

Finally, we evaluate in-sample and out-of-sample forecasting performances of the MS-ARFIMA, Markov Switching and ARFIMA models. Results show that the MS-ARFIMA model supplants the two other models since it presents the lower RMSE. Main results from Hanse (2005) SPA test shows that the MSARFIMA model outperforms the markov switching one as well as the pure long memory process

The extension of the Markov Switching to the MS-ARFIMA model by introducing fractional integration in each regime has important implications. Our results could bring significant improvement in the area of asset allocation and risk hedging seen the recurrent application of regime switching models in hedge fund literature. More broadly we suggest that understanding the interaction between hedge funds and standard asset markets should be based on the characteristics of each regime. An extension of this work to a multivariate framework could come up with some answers concerning the dependence structure between hedge funds themselves and hedge funds and stock markets. 
Figure 2a-2j: Estimated $d_{s_{t}}$ for the CSFB/Tremont hedge funds indexes.
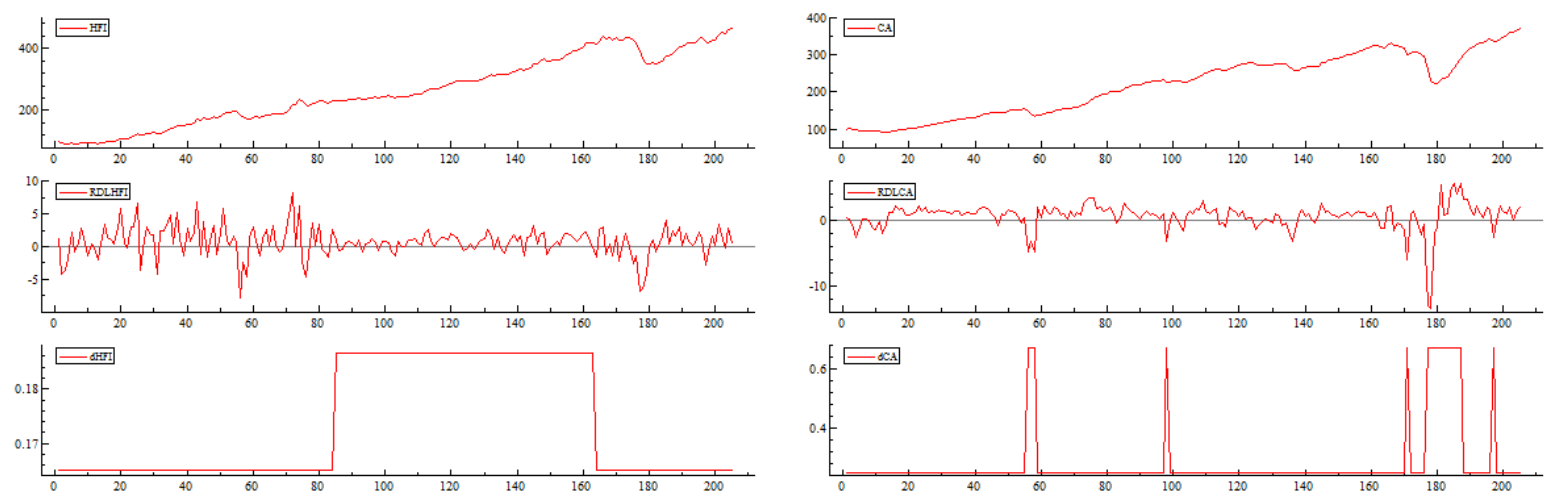

Figure 2a. Hedge FundcIndex

Figure 2b. Convertible Arbitrage
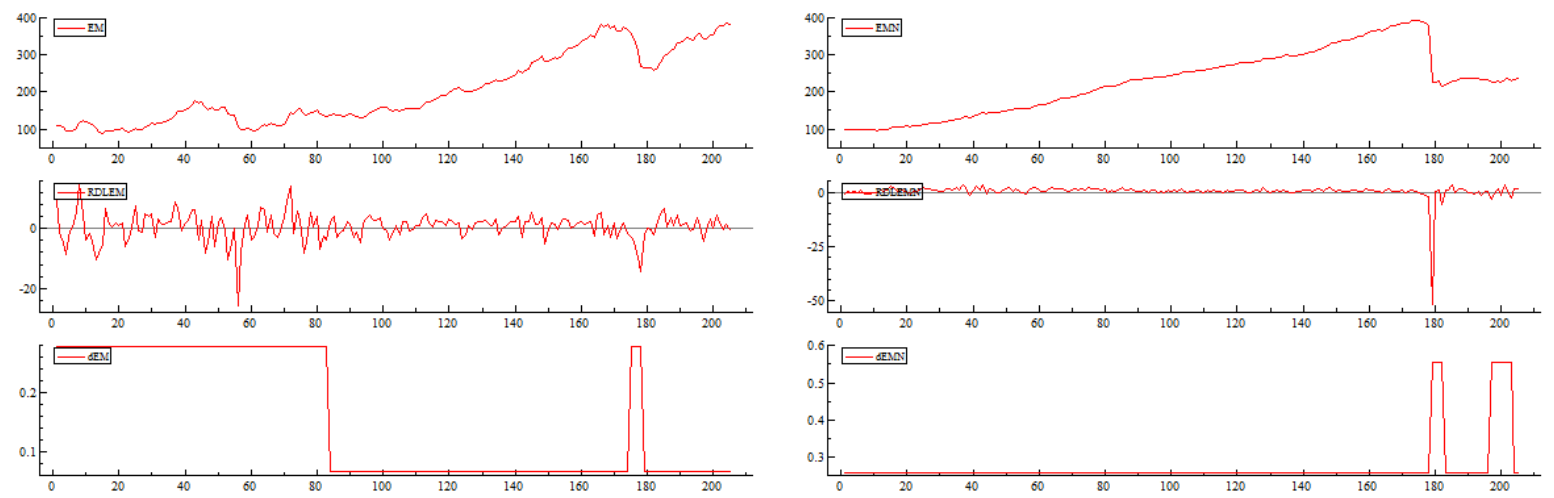

Figure 2c. Emerging Markets

Figure 2d. Equity Market Neutral
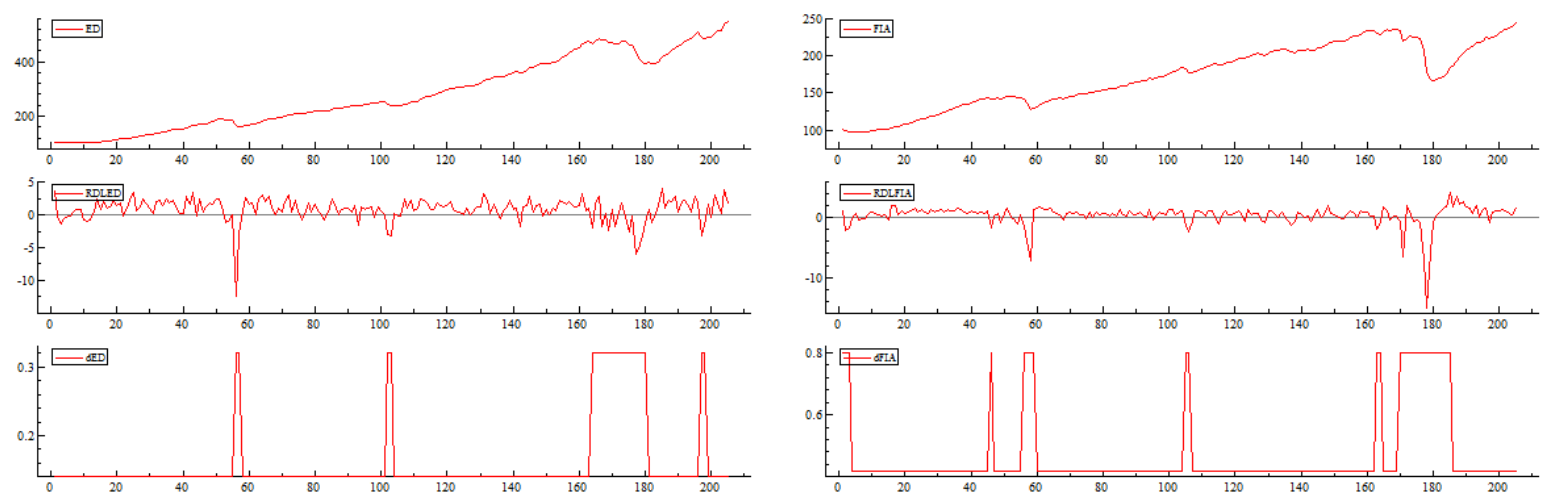

Figure 2e. Event Driven

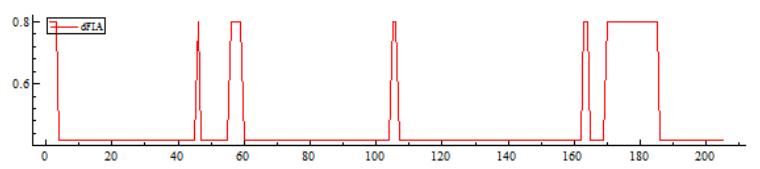

Figure 2f. Fixed Income Arbitrage 

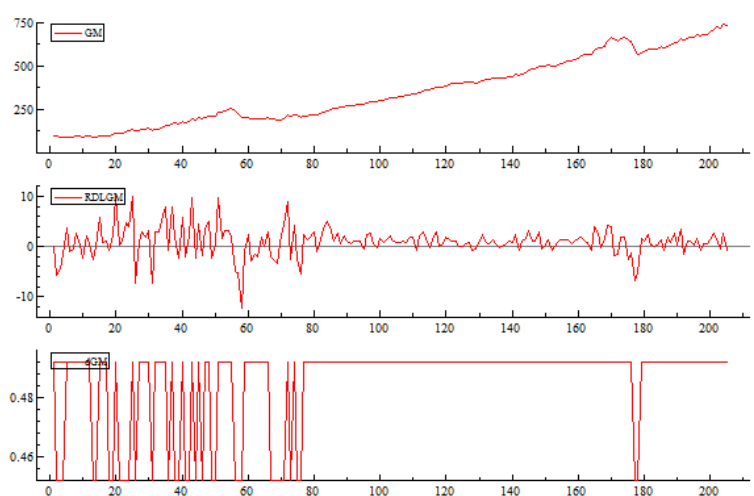

Figure 2g. Global Macro
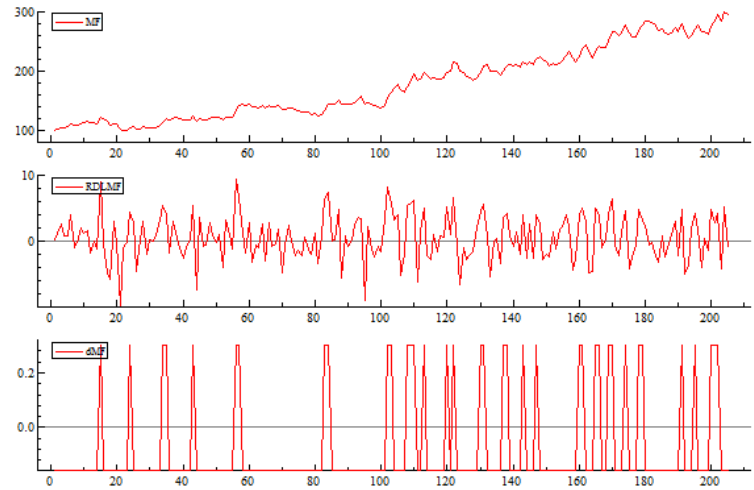

Figure 2i. Managed Futures
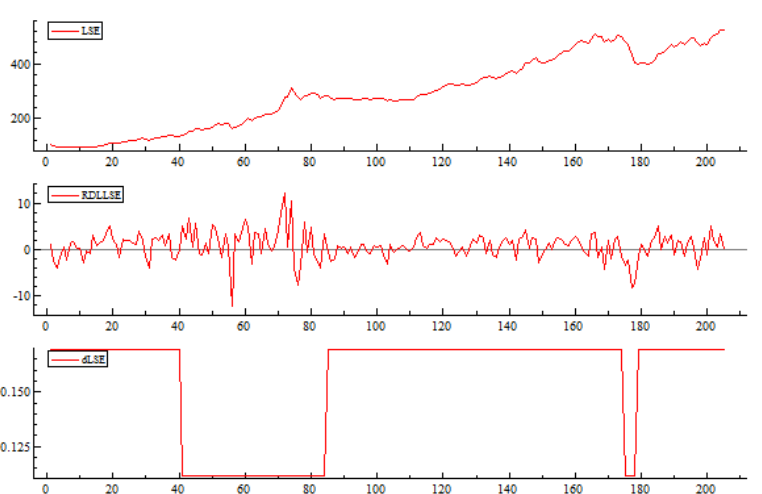

Figure 2h. Long Short Equity
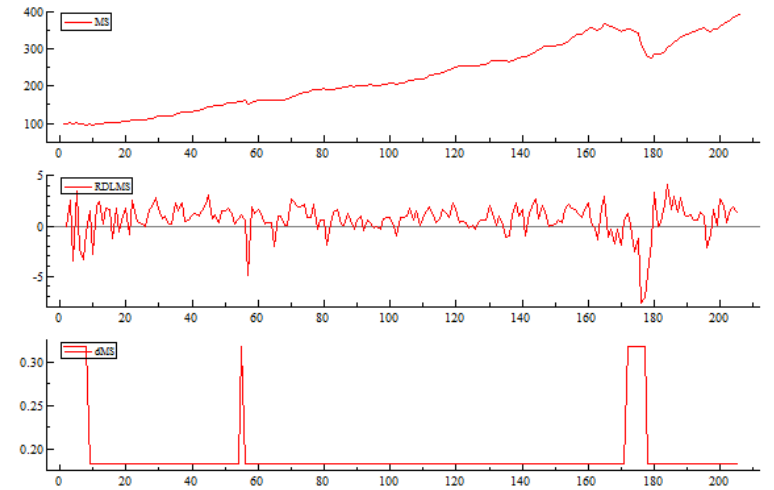

Figure 2j. Multi-Strategy 


\section{References}

Abry P., and Veitch D., (1998). Wavelets Analysis of Long Range Dependent Traffic, IEEE Transactions on Information Theory, 44(1), 2-15.

Ackermann, C., R. McEnally, and Ravenscraft, D., (1999). The Performance of Hedge Funds: Risk, Return, and Incentives, Journal of Finance, 54(3), 833-874.

Amenc, N., El Bied, S., and Martellini, L., (2003). Evidence of Predictability in Hedge Fund Returns, Financial Analysts Journal, 59(5), 32-46.

Baillie R.T., (1996). Long Memory Processes and Fractional Integration in Econometrics, Journal of Econometrics, 73(1), 5-59.

Bauwens, L., and Sucarrat, G., (2010). General-to-specific modelling of exchange rate volatility: a forecast evaluation. International Journal of Forecasting, 26(4), 885-907.

Beran, J., (1994). Statistics for Long Memory Processes. Chapman and Hall, New York

Brown, S. and W. Goetzmann,(1995). Performance Persistence, Journal of Finance, Vol. L, No 2, . 679-698.

Davidson, J., (2004), Forecasting Markov-switching dynamic processes, Statistics and Probability Letters, 68(2), 137-147.

Davidson, J., (2005). Time series modeling version 4.15,

<http://www.timeseriesmodeling.com/>

Fung, W. and D. Hsieh, (1997). Empirical Characteristics of Dynamic Trading Strategies: The Case of Hedge Funds, Review of Financial Studies, 275-302.

Geweke J. and Porter-Hudak S., (1983). The estimation and Application of Long Memory Time Series Models, Journal of Time Series Analysis, 4(4), 221-238.

Granger, C., Joyeux, R., (1980). An introduction to long memory time series models and fractional differencing. Journal of Time Series Analysis 1, 15-29.

Granger. C. W. J.. Hyung. N.. (2004). Occasional structural breaks and long memory with an application to the S\&P 500 absolute stock returns. Journal of Empirical Finance, 11, 399421.

Haldrup. N.. Nielsen. M... (2007). Estimation of fractional integration in the presence of data noise. Computational Statistics \& Data Analysis. 51. 3100-3114.

Hamilton, J., (1989). A new approach to the economic analysis of nonstationary time series and the business cycle. Econometrica 57, 357-384.

Hamilton, J., (1990). Analysis of time series subject to changes in regime. Journal of Econometrics 45, 39-70. 
Hansen, P.R. (2005). A test for superior predictive ability. Journal of Business \& Economic Statistics, 23, 365-380.

Hosking, J., (1981). Fractional differencing. Biometrika 68, 165-176

Hübner, G., G. Gregoriou, N. Papageorgiou and F. Rouah, (2005). Hedge Funds: Insights in Performance Measurement, Risk Analysis, and Portfolio Allocation, J. Wiley \& sons.

Hurst H.E. (1951). Long-Term Storage Capacity of Reservoirs, Transactions of the Americain Society of Civil Engineers, 116, 770-799.

Lavancier, F., Leipus, R., Philippe, A., Surgailis, D., (2013). Detection of non-constant long memory parameter. Econometric Theory, 29(5):1009-1056.

Lhabitant, F. S. (2004). Hedge Funds: Quantitative Insights. Hoboken, NJ: John Wiley \& Sons.

McCloskey. A. \& Perron. P. (2010). Memory parameter estimation in the presence of level shifts and deterministictrends. Unpublished Manuscript. Department of Economics. Boston University.

Mills T.C., (1990). The Economic Modeling of Financial Time Series, Cambridge University Press.

Perron, P. (1989), The Great Crash, the Oil Price Shock, and the Unit Root Hypothesis, Econometrica 57, 1361-1401.

Perron. P.. Qu. Z.. (2010). Long-Memory and Level Shifts in the Volatility of Stock Market Return Indices. Journal of Business \& Economics Statistics. 28(2). 275-290.

Qu. Z. (2011). A test against spurious long memory, Journal of Business and Economic Statistics, 29. 423-438

Ray. B. K. and Tsay. R. S. (2002). Bayesian estimation for change-point detection in longrange dependent processes, Journal of Time Series Analysis 23. 687-705.

Robinson, P., (2003). Time Series with Long Memory. Oxford University Press, Oxford

Shimotsu K. (2006) Simple (but effective) tests of long memory versus structural breaks. Queen's Economics Department. Working Paper No. 1101

Shimotsu, K., and Phillips, P., (2006). Local Whittle estimation of fractional integration and some of its variants. Journal of Econometrics 130, 209-233.

Tsay, W., and Härdle, W., (2009). A generalized ARFIMA process with Markov-Switching fractional differencing parameter. Journal of Statistical Computation \& Simulation 79, 731745. 
Zivot, E., and D. Andrews D.W.K. (1992). Further Evidence of Great Crash, the Oil Price Shock and Unit Root Hypothesis, Journal of Business and Economic Statistics, 10, 251270. 